\title{
SUPPORTING FORCES AND STABILITY OF SNOW-SLAB AVALANCHES: A PARAMETER STUDY
}

by

\author{
Bernhard Lackinger
}

(Institut für Bodenmechanik, Felsmechanik und Grundbau, Universität Innsbruck, Technikerstrasse 13, A-6020 Innsbruck, Austria)

\section{ABSTRACT}

The fracture of a slab avalanche is a multi-phase and progressive process. The different kinds of fracture and possible scenarios of avalanche release in the form of a zip effect are shown. In the course of investigations, most importance has so far been attached to shear failure along the sliding surface. Various cases of load and their effects on the stresses, on the changes of strength, and on the stability of the inclined snow-pack are discussed. The usual simple model of the shear-stability index is unsatisfactory, The present paper deals with the complex interaction of all supporting forces of a snow slab by means of simplified geotechnical considerations. For this purpose, the acting and reacting forces of a "standard avalanche" (i.e. dead load with driving and normal component, shear force, tensile force, compressive force, and flank force) are estimated from published boundary values. Using different combinations (e.g. hard slab with high circumferential forces on a weak shear surface with low shear force), it can be shown that suspension at the crown and lower and latera support are of great importance. This applies especially to cases with low shear forces and, consequently, with low overall stability. Despite the fact that the circumferential area of the model avalanche is only $6 \%$ of the area of the shear surface, the circumferential force in this case is more than $150 \%$ of the shear force. In a parameter study with different avalanche sizes, these results are generalized and confirmed. For the assumed strength limits, critical areas and depths of possible slab avalanches can be derived. Although the supporting shear force is the major contributor to stability, particularly with larger slabs, it can be seen from the investigations that the redistributions of stress and spatial supports and suspensions of the whole slab avalanche must not be neglected in stability analyses.

\section{INTRODUCTION AND SETTING OF THE PROBLEM}

Each winter's contest between stresses and strengths in an inclined snow-pack leads to many avalanches in moutainous areas with a serious death toll and extensive damage to property. Therefore, the fracture mechanism of avalanches and the mechanical stability of the snow cover are very important for avalanche forecasting and other applications, e.g. estimating the time for closing roads or ski runs, for choosing the correct route for skiers, or for artificial triggering of avalanches.

The fracture of a slab avalanche (Fig. 1) is a multistage, progressive, and very fast-running process, details of which are still clouded with many secrets. Among the unknowns are the locally and temporally varying tensile, compressional, and shear stresses, and also the resisting strengths, as they cannot be measured directly because of the specific properties of the snow and the severe danger involved. Because of the topographic relief and the specific build-up of the snow cover in the course of a winter, its stability across a potential avalanche area is variable both in space and time. Therefore, idealized models, limiting considerations, and separate investigations of each stage of

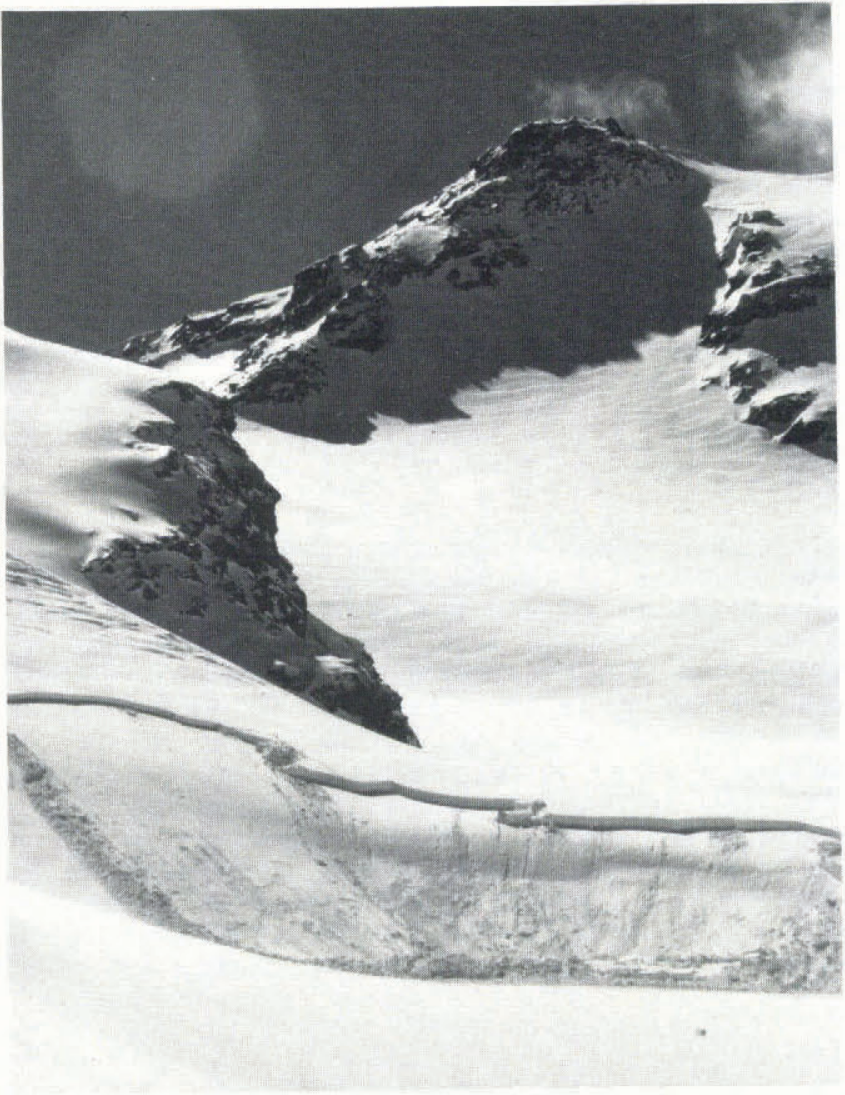

Fig. 1. Slab avalanche (Piz Sesvenna, 25 March 1986); triggered by a group of skiers at a distance of $200 \mathrm{~m}$.

this complex process are needed. The present simplified model deals only with the fracture process itself in a geotechnical manner. The preceding avalanche "maturing" will be touched on briefly, where necessary.

\section{STAGES OF FRACTURE}

In response to the variety of forces along its boundaries (Figs 1 and 2), a snow-slab avalanche fractures in several stages.

\subsection{Shear fracture}

The shear fracture along the shear interface, which is more or less parallel to the surface, is the most important as regards the area, and is therefore considered to be the primary fracture by most experts. The development leading up to the failure of the entire shear surface is characterized by the large deformability of snow under shear stresses, and the resulting dissipative processes. Therefore, the strength depends heavily (i.e. inversely) on the strain-rate. Following 


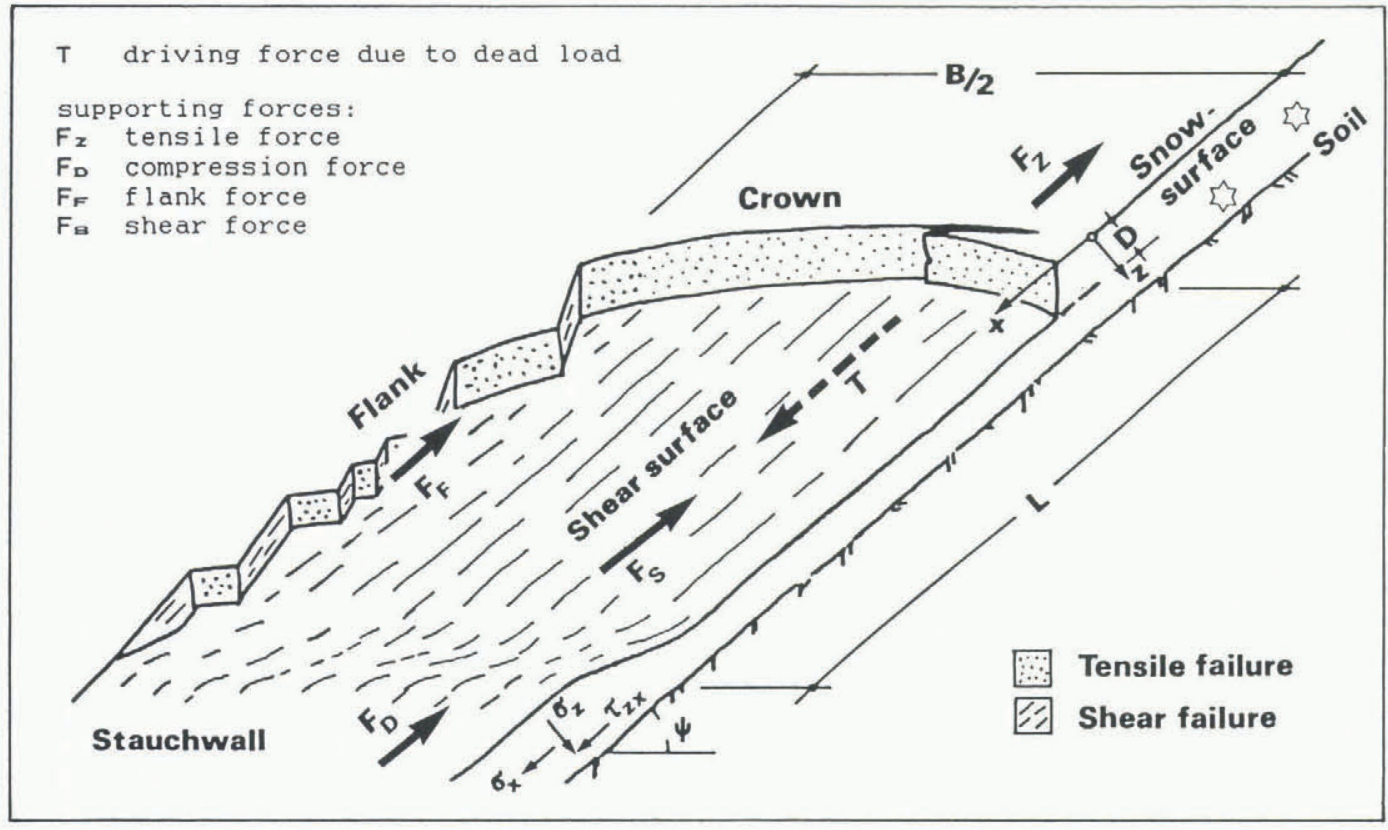

Fig. 2. Slab avalanche: definitions, coordinate system, acting forces. $T$ is driving force due to dead load. Supporting forces: $F_{z}$, tensile force; $F_{\mathrm{D}}$, compression force; $F_{\mathrm{F}}$, flank force; $S_{\mathrm{S}}$, shear force.

Gubler (1977, 1988), the initial fracture along a limited weak zone of the shear surface requires that a minimal strain-rate be exceeded such that the ductile initial strength may be overcome. Further propagation of the fracture then occurs as a brittle fracture quasi-elastically at high deformation rates. In the course of this progression, therefore, two quite different strengths play a role, one being the higher initial strength (at low strain-rate), and the other the lower brittle strength (at a very fast deformation speed in the course of the crack's expansion). The question to what extent the actual shear strain is important - with granular media, as we know, a certain shearing displacement is required to activate the shear strength - appears to be unresolved.

Weakening and failure of the shear surface may be caused by:

Increasing stresses and consequent higher strain-rates, caused by loading (snow precipitation, skiers), or redistribution of stresses.

Local strain softening of the snow caused by heterogeneous deformations.

Decreasing grain connections caused by TG metamorphism or melting processes.

Temperature rising with strength decreasing.

Collapse of a depth-hoar layer (especially in areas with a continental climate).

\subsection{Tensile fracture}

The tensile fracture at the crown of the snow-slab avalanche - the secondary fracture in most cases - is a cleavage fracture, which is determined by the rather brittle deformation characteristics of snow under tension. This fact gives many reasons for believing that here could be primary fracture (e.g. Haefeli, 1963, 1967; Sommerfeld, 1969). As opposed to the shearing zone, which is of ten only a few millimetres thick, here the properties of the snow cover in its entire depth, consisting of layers with varying tensile strengths and deformability, come into play. Stress concentrations are built up in stiffer layers, also causing the fracture process to be progressive in this case. This effect is superimposed by the fact that the crown's height is frequently not uniform.

\subsection{Flank fracture}

During flank fracture, which is the third phase, shearfracture mechanisms and tensile-fracture mechanisms overlap. As a consequence, we find different aspect angles between the lateral flanks and the down-slope direction (Fig. 2).

\subsection{Compressive fracture}

Finally, following considerable compression of the snow at the stauchwall, compressive fracture will occur as shearing across the whole snow cover. Here again, what matters are the strength properties of the various snow layers involved.

\section{STRESS REDISTRIBUTIONS AND PROPAGATION OF THE FAILURE}

\subsection{Primary fracture of a thin shear layer}

Before the initial fracture (see section 2.1) occurs, there is an equilibrium state between the driving stresses and the shear, tensile, and compressive strengths, of which different fractions are activated. When the shear strength $\beta_{S}$ drops by $\Delta \beta_{S}$ or ceases altogether in the initial fracture zone (of slope-parallel length $\Delta x$ ), the fraction which is no longer transmitted down into the deeper snow layers (for each metre width of the slab)

$$
\Delta F_{\mathrm{S}}=\Delta \beta_{\mathrm{s}} \Delta x
$$

must be supported by larger circumferential forces in the snow layers above the shear surface. If these are tensile forces, the tensile stress $\sigma_{x}$, on average, is increased by

$$
\Delta \sigma_{x}=\Delta \beta_{s} \Delta x / D
$$

where $D$ is thickness of snow-pack (normal to the surface).

This leads to increased stresses near the initial fracture zone, which may either be transmitted down into deeper snow layers when the shear strength in the surrounding zone is high enough (in which case the shear fracture is stopped), or they may also cause a shear fracture here. Because of this propagating shear fracture, the tensile stresses accumulate to the point where the tensile strength of the snow-pack is reached and the tensile fracture is initiated. It will be shown later that the developing slab avalanche is greater the stronger the snow layers are above the shear surface.

\subsection{Collapse of a thick layer (e.g. depth hoar)}

Depth hoar at the bottom has a texture with coarse pores, large snow crystals, and few points of contact for transmitting forces. At higher stress, collapse of the texture may occur due to a local compressive failure, immediately preceding the avalanche fracture itself (see Bucher, 1948; or Bradley and others, 1977). In the case of depth-hoar 
collapse, which causes compression of the depth hoar along with a decrease of the shear strength, we may imagine a variety of complex failure mechanisms:

(a) The collapse of texture leads to a loss of cohesion (mostly small to start with) in the basal layer, which cannot be compensated for by increased friction due to denser packing of the snow grains. Shear strength decreases and, consequently, the shear fracture widens across the basal layer much as in the case of thin shear layers, until circumferential fractures set in.

(b) The collapse of texture is accompanied by compression. If there is a stiff upper layer, the compression leads to a state in which the upper layer locally becomes detached from the basal layer, being subjected to bending forces. The area of bending widens along with the lateral propagation of the collapse. A certain part of the upper layer may remain hollow without breaking, but its size depends on its bending tensile strength, its thickness, the load, and the support conditions. Before the simultaneous failure of the shear support leads to fracture propagation, as in case (a), the bending strength is exceeded and cracks across the upper layer interrupt the lateral and longitudinal force transmission. Thus, the circumferential support, being already severely stressed by the failure of the shear support, collapses entirely. Fracture of the slab avalanche becomes unavoidable.

Preliminary investigations of a circular slab supported along the edges have shown that the bending tensile stresses at the snow surface along the edges due to the slab's own weight and the effect of clamping are probably larger than those in the middle of the lower side. Therefore, the bending tensile cracks begin at the snow surface. No values have been found in the literature for the bending strength of snow. An investigation of the fracture mechanics of these processes is being planned for the future.

\section{STABILITY AGAINST SHEAR FRACTURE}

As a rule, especially for practical purposes, the slope stability is investigated solely with respect to the possible shear fracture in the neutral zone, disregarding the boundary conditions along the entire snow-slab avalanche, as well as the fracture's progressive character. This means that, for the potential shear surface, a stability factor is formed (really a safety factor in the technical sense). $s$ is the ratio of the shear strength $\beta_{\mathrm{s}}$ to driving shear stress parallel to the slope $\tau_{z x}$ (Roch, 1966a; Föhn, 1981, 1987; Conway and Abrahamson, 1984):

$$
s=\beta_{s}\left(\sigma_{z}\right) / \tau_{z x} .
$$

Normal and shear stresses are obtained from the dead load in the special case after Rankine (activated friction angle equals slope angle):

$$
\begin{aligned}
\sigma_{z} & =\rho g D \cos \psi, \\
\tau_{z x} & =\rho g D \sin \psi .
\end{aligned}
$$

Here, we use the notation: $\rho$ is mean density of the snow-pack, $D$ is thickness of the snow-pack (normal to the surface), $\psi$ is slope inclination, and $g=10 \mathrm{~m} / \mathrm{s}^{2}$.

If there is an additional load (component parallel to the slope $\Delta \tau_{z x}$ ), caused by snowfall, snowdrift, skiers, snowmobiles, or avalanche blasting, the stability changes as follows:

$$
s^{\prime}=\beta_{\mathrm{s}} /\left(\tau_{z x}+\Delta \tau_{z x}\right) .
$$

Usually $\beta_{\mathrm{S}}$ is determined from in situ shear-frame tests, the values therefore being rather inaccurate. Also, $\beta_{S}$ may change, e.g. due to loads which increase $\sigma_{z}$ :

$$
s^{\prime}=\left(\beta_{S} \pm \Delta \beta_{S}\right) /\left(\tau_{z x}+\Delta \tau_{z x}\right) .
$$

In Equation (6), a possible change in the strength $\Delta \beta_{\mathrm{S}}$ has been included. The Mohr diagram (Fig. 3) is a graphical

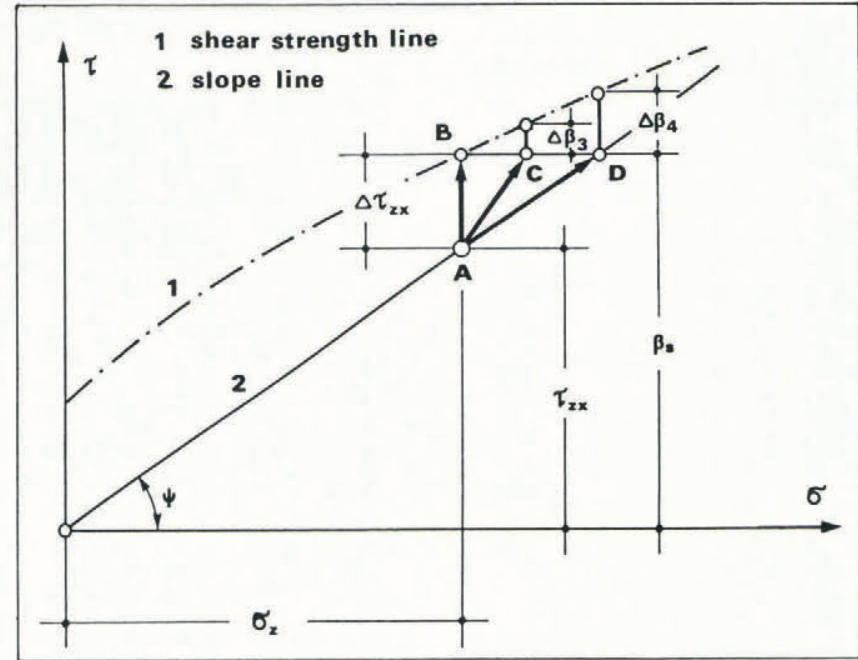

Fig. 3. Stability of the snow-pack against shear failure for varying load cases (Mohr's diagram): A, dead load $s_{\mathrm{A}}=\beta_{\mathrm{S}} / \tau_{z x}>1 ; \quad \mathrm{B}$, increase of shear stress $s_{\mathrm{B}}=\beta_{\mathrm{S}} /\left(\tau_{z x}+\Delta \tau_{z X}\right)>1 ; \mathrm{C}$, load caused by a skier $s_{\mathrm{C}}=\left(\beta_{\mathrm{S}}+\Delta \beta_{3}\right) /\left(\tau_{z x}+\Delta \tau_{z X}\right)>1 ; \mathrm{D}$, load caused by snowfall $S_{\mathrm{D}}^{\prime}=\left(\beta_{\mathrm{S}}+\Delta \beta_{4}\right) /\left(\tau_{z x}+\Delta \tau_{z x}\right)>1$.

representation of Equations (5) and (6) for varying loads. The shear-strength line (Coulomb-Mohr) is taken to be invariable.

Föhn $(1981,1987)$ investigated mainly the amount of additional tangential stress (load case $B$ in Figure 3 ) and the changes in stability, particularly in the case of avalanche blasting, but at the same time disregarding the changes of strength due to the increased normal stresses or to dynamic effects in the snow-pack.

As proof of the fact that the method based on the stability factor is unsatisfactory, we take the results that Roch (1966a), as well as Conway and Abrahamson (1984), with their improved experimental technique obtained shear stabilities up to 4 (with a very large scatter) even when the avalanche had fractured. This can partly be explained by the fact that strengths are particularly variable across short distances. A similarly large variance is, no doubt, true for the stresses. Föhn (1987) stated: "..., the method reveals still too many deficiencies." Apparently, locally restricted considerations of strength and stress are insufficient for describing the overall stability of a slope. Therefore, in the following, we will consider the total potential avalanche.

\section{SUPPORTING FORCES ACTING ON A SNOW SLAB}

5.1. The "standard" snow-slab avalanche

Although we are aware of the complex and heterogeneous conditions, we are trying to estimate the balance of forces acting on a snow slab by adding up individual contributions. By this means, we are neglecting the sequence of the above-described fracture phases and their exact course, especially progressive processes and stress redistributions. We will try to model important factors such as the suspension of the slab at the crown, its support at the stauchwall, and boundary influences from the flanks in relation to the forces along the shear surface by using a simplified "standard avalanche". The following forces act along the down-slope direction (Fig. 2): $T$ is the driving component of the total weight $G, F_{z}$ is the tension force at the crown, $F_{\mathrm{D}}$ is the compression force at the stauchwall, $F_{F}$ is flank force, $F_{S}$ is shear force along the shear surface.

According to Perla $(1977,1980)$ and Föhn (1981), the standard avalanche is characterized by the following values: $B=50 \mathrm{~m}$ (width of avalanche), $L=50 \mathrm{~m}$ (length of avalanche), $D=0.7 \mathrm{~m}$ (thickness of avalanche), $\quad \phi=38^{\circ}$ (slope inclination), and $\rho=220 \mathrm{~kg} / \mathrm{m}^{3}$ (density of snow (valid also below the sliding surface)). 
The following active forces may be derived:

$G=\rho g B L D=3850 \mathrm{kN}$ (total weight of avalanche), (7)

$T=G \sin \psi=2370 \mathrm{kN}$ (slope-parallel component),

$N=G \cos \psi=3034 \mathrm{kN}$ (normal component).

Following Mellor (1975, figs 17 and 18), we obtain limiting values of the tensile, compressive, and shear strengths for snow density of $220 \mathrm{~kg} / \mathrm{m}^{3}$. These values are shown in Table I below. This table also contains the

TABLE I. LIMITS FOR SUPPORTING FORCES ACTING ON A TYPICAL SNOW SLAB ("STANDARD AVALANCHE" OF AREA $50 \times 50 \mathrm{~m}^{2}$, THICKNESS $0.7 \mathrm{~m}$, $\rho=220 \mathrm{~kg} / \mathrm{m}^{3}, \quad \psi=38^{\circ}, \quad$ AND STRENGTHS AS DISCUSSED IN THE TEXT)

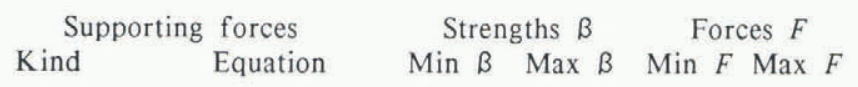

\begin{tabular}{|c|c|c|c|c|}
\hline & Unit & $\mathrm{kPa}$ & $\mathrm{kPa}$ & $\mathrm{kN}$ \\
\hline Tension & $F_{z}=B D B_{z}$ & 3 & 15 & 105 \\
\hline Compression & $F_{\mathrm{D}}=B D \beta_{\mathrm{D}}$ & 5 & 20 & 175 \\
\hline Flanks & $F_{\mathrm{F}}=2 L D B_{\mathrm{F}}$ & 2.5 & 10 & 175 \\
\hline $\begin{array}{l}\text { Circumfer- } \\
\text { ence }\end{array}$ & $\begin{aligned} F_{\mathrm{U}}= & F_{z}+F_{\mathrm{D}}+ \\
& +F_{\mathrm{F}}\end{aligned}$ & - & - & 455 \\
\hline Shear & $F_{\mathrm{S}}=B L \beta_{\mathrm{S}}^{\mathrm{r}}$ & 0.5 & 5 & 1250 \\
\hline
\end{tabular}

computation of minimal and maximal supporting forces of the standard snow slab.

The equation for the uniaxial tensile strength $B_{z}$ is accepted, being justified by the mechanism of cleavage fracture. The simplified computation for the stauchwall with the uniaxial compressive strength $\beta_{D}$ has been checked by investigating a shear fracture across the snow-pack, similar to passive Earth pressure. Following Ziegler (1963) and applying the Tresca criterion for fracture

$$
c=1 / 2 B_{D},
$$

we compute the slope-parallel supporting force at the stauchwall as

$$
F_{\mathrm{D}}=1 / 4 \beta_{\mathrm{D}} \cot (\psi+\pi) D B
$$

with limiting values $193<F_{\mathrm{D}}<774 \mathrm{kN}$. Compared to Table I with $175<F_{\mathrm{D}}<700 \mathrm{kN}$ (calculated with $\beta_{\mathrm{D}}$ ), there is a difference of only roughly $10 \%$. The complete solution for the inclined half-space including the internal friction is too cumbersome in the present context and changes the force $F_{\mathrm{D}}$ only slightly (Kupper, 1967). The Tresca criterion was also applied to the cohesion $\beta_{F}$ of the flanks.

If, in place of the Tresca criterion (as in Table I: $\beta_{S}=c=$ constant), we use the Coulomb-Mohr equation for obtaining the shear strength of the shear surface, we obtain for the chosen standard avalanche the limits for $\beta_{s}$ as 0.4 and $2.6 \mathrm{kPa}$, respectively, following Föhn's (1981) analyses based on papers by Roch $(1966 \mathrm{a}, \mathrm{b})$. The limits of strengths shown in Table I may, therefore, be considered as the right order of magnitude.

The computed minimal and maximal forces from Table I may now be related to different avalanche scenarios, such that the restraining shear forces $F_{\mathrm{S}}$ may combine in various ways with the supporting circumferential forces $F_{\mathrm{U}}$

$$
F_{\mathrm{U}}=F_{z}+F_{\mathrm{D}}+F_{\mathrm{F}} .
$$

We distinguish between an internally strong snow slab (e.g. formed by wind compaction) and a snow slab of low strength consisting of loose snow, and further between a solid substrate well connected with the snow slab, and a weak shear surface (e.g. hoar frost being snowed in). The various possible combinations of suporting forces and the respective integral stabilities:

$$
\bar{s}=\left(F_{\mathrm{U}}+F_{\mathrm{S}}\right) / T
$$

are put together in Table II.

Taking the combination with minimal shear force in the second-to-last line of this table, a case which may occur with heavy snowfall, we see from $\bar{s}=0.72$ that fracturing of the snow-slab avalanche is unavoidable unless

TABLE II. COMBINATIONS OF THE SUPPORTING FORCES FOR VARYING AVALANCHE SCENARIOS AND INTEGRAL STABILITIES FOR THE STANDARD SNOW SLAB

Property of Circum- Property Shear $F_{\mathrm{U}} / F_{\mathrm{S}} \quad \bar{s}=$ snow slab ferential of shear force force $F_{\mathrm{U}}$ surface $\quad F_{\mathrm{S}}$ $\left(F_{\mathrm{U}}+F_{\mathrm{S}}\right) / T$

\begin{tabular}{lrlrrr}
\multicolumn{1}{c}{ Unit } & $\mathrm{kN}$ & & $\mathrm{kN}$ & $\%$ & 1 \\
& & & & & \\
Strong & 1925 & Weak & 1250 & 154 & 1.34 \\
Strong & 1925 & Strong & 12500 & 15 & 6.09 \\
Weak & 455 & Strong & 12500 & 4 & 5.47 \\
Weak & 455 & Weak & 1250 & 36 & $0.72 !$ \\
Strong & $1225^{*}$ & Weak & 1250 & 98 & 1.04
\end{tabular}

$* F_{\mathrm{U}}=F_{z}+F_{\mathrm{F}}$.

additional supporting forces can be activated, for example vaulting with additional lateral support or support at protrusions in the relief.

The last line of Table II refers to a combination with minimal shear force, whereby the pressure force at the stauchwall has been disregarded because much deformation is needed to activate it. Here, despite the large tensile and flank forces, integral stability barely exceeds 1 . This reinforces the overwhelming importance of the shear strength.

It has frequently been assumed that the influence of the boundaries is negligible due to their small contribution to the total area; for the standard avalanche, the circumferential surface is only $5.6 \%$ of the shear surface, but for many real avalanches it is even less. The above conclusion, however, may be quite erroneous; taking the ratio $F_{\mathrm{U}} / F_{\mathrm{S}}$ as a measure of the boundary contribution to the support of a snow-slab avalanche, this ratio (from Table II) is indeed only $4-15 \%$ at high stability (which tends to prevent avalanche fracture), but increases rapidly to $36-154 \%$ in the critical cases of low stability which are of particular interest.

\subsection{The parameter study}

Generalizing the computations (Tables I and II), a parameter study has been undertaken using the following constants and variables:

Constants

Density $\quad \rho=220 \mathrm{~kg} / \mathrm{m}^{3}$ (see note (a))

Circumferential strengths $\beta_{z}, B_{D}, \beta_{F} \ldots$ minima and maxima for each (from Table I)

Shear strength $\beta_{\mathrm{S}}=0.5 \mathrm{kN} / \mathrm{m}^{2} \ldots$ minimum (see note (b))

Slope inclination $\psi=38^{\circ}$ (see note (c))

Variables

Width $B=$ length $L(10 \mathrm{~m} \leqslant B \leqslant 110 \mathrm{~m})$

Thickness $D(0.4 \mathrm{~m} \leqslant D \leqslant 1.5 \mathrm{~m})$

Note (a). In a comparative investigation for higher density and disproportionately higher strengths (see Mellor, 1975), stabilities $\bar{s}$ worked out to be many times higher; these values are therefore not relevant. For lower densities and 


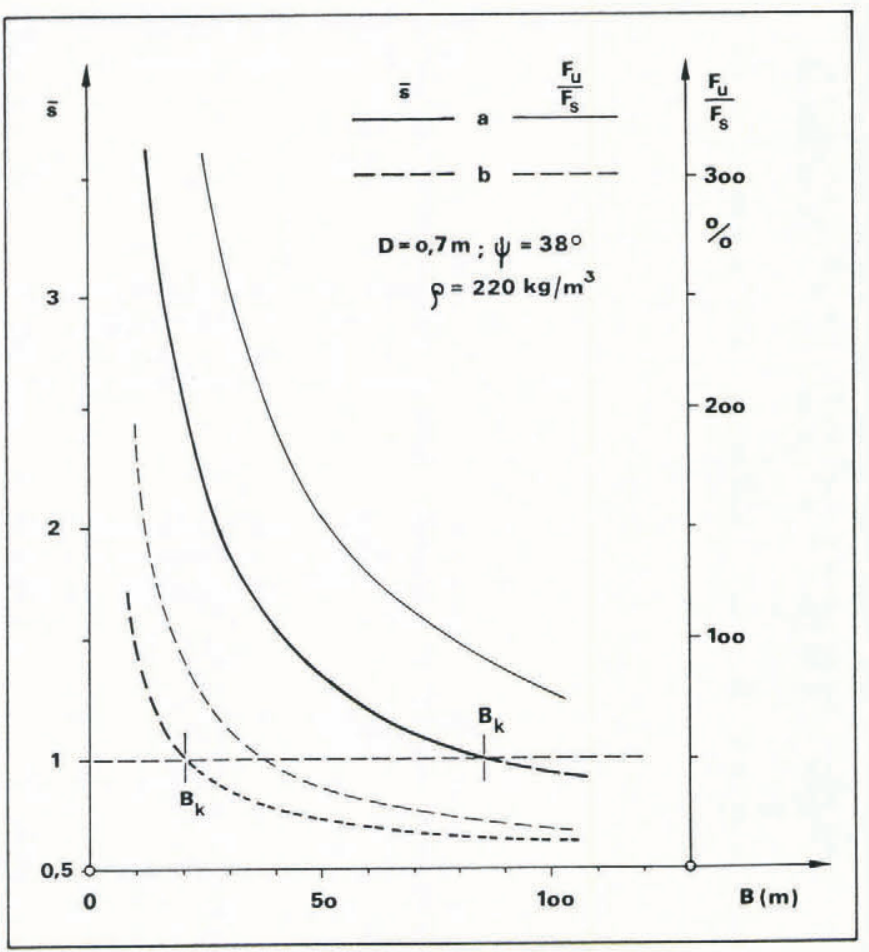

Fig. 4. Integral stability $\bar{s}$ and ratio of the circumferential force to the shear force $F_{\mathrm{U}} / F_{\mathrm{S}}$ of a snow slab as a function of their width $B=$ length $L$.

a, strong slab, weak shear surface, $\}$ see Tables I $\mathrm{b}$, weak slab, weak shear surface, $\}$ and II $B_{\mathrm{K}}$, critical width $(\bar{s}=1)$.

consequently lower strengths, applicable particularly to newsnow avalanches, there are hardly any physical parameters in the literature.

Note (b). As shown already in Table II, no avalanche releases may be expected with high shear strengths.

Note (c). Varying the slope inclination angle by $\pm 6^{\circ}$, and retaining all other parameters and $H=D / \cos \psi=$ constant, resulted in a change in stability $\bar{s}$ of only roughly $\pm 10 \%$ for the "standard avalanche".

Overall stability for $B=L$ is obtained from the forces according to Table I and Equation (13):

where

$$
\bar{s}=\left(\beta_{\mathrm{U}} / B+\beta_{\mathrm{S}} / D\right) / \rho g \sin \psi
$$

$$
\beta_{U}=\beta_{z}+\beta_{D}+2 \beta_{F} .
$$

Varying the width or the shear surface area $\left(B=\left(A_{\mathrm{S}}\right)^{\frac{1}{2}}\right)$, and keeping the slab's thickness $D=0.7 \mathrm{~m}$ constant, gives the results shown in Figure 4. It can be seen from the approximately hyperbolic curve shape for $\bar{s}$ as well as for $F_{\mathrm{U}} / F_{\mathrm{S}}$ that, with increasing size of the slab, the circumferential forces' supporting role weakens considerably; their contribution, however, remains above $70 \%$ of the shearing force in this case with a weak shear surface. Even so, the circumferential forces can prevent fracture only up to a certain critical width $B_{\mathrm{K}}(\bar{s}=1)$, because beyond this point-force transmission becomes impossible due to the preceding circumferential fracture. $B_{\mathrm{K}}$ increases considerably with increasing circumferential strengths (see Figs 4 and 6). Stronger, wind-blown slab avalanches with proportionately larger circumferential forces $\left(90-300 \%\right.$ of $\left.F_{S}\right)$ may, therefore, fracture as a whole large area, even when the shear surface is weak.

The influence of varying depths on $\bar{s}$, retaining the width constant, is shown in Figure 5. Stability decreases with increasing depth, this decrease being more pronounced the larger and weaker the slab. The distance between the two lines for a strong and a weak slab, respectively, is a measure of how the circumferential forces matter more for smaller slabs. Upon reaching the critical depth $D_{\mathrm{K}}$ the slab avalanche fractures; this point is reached sooner both with weak and with large slabs.
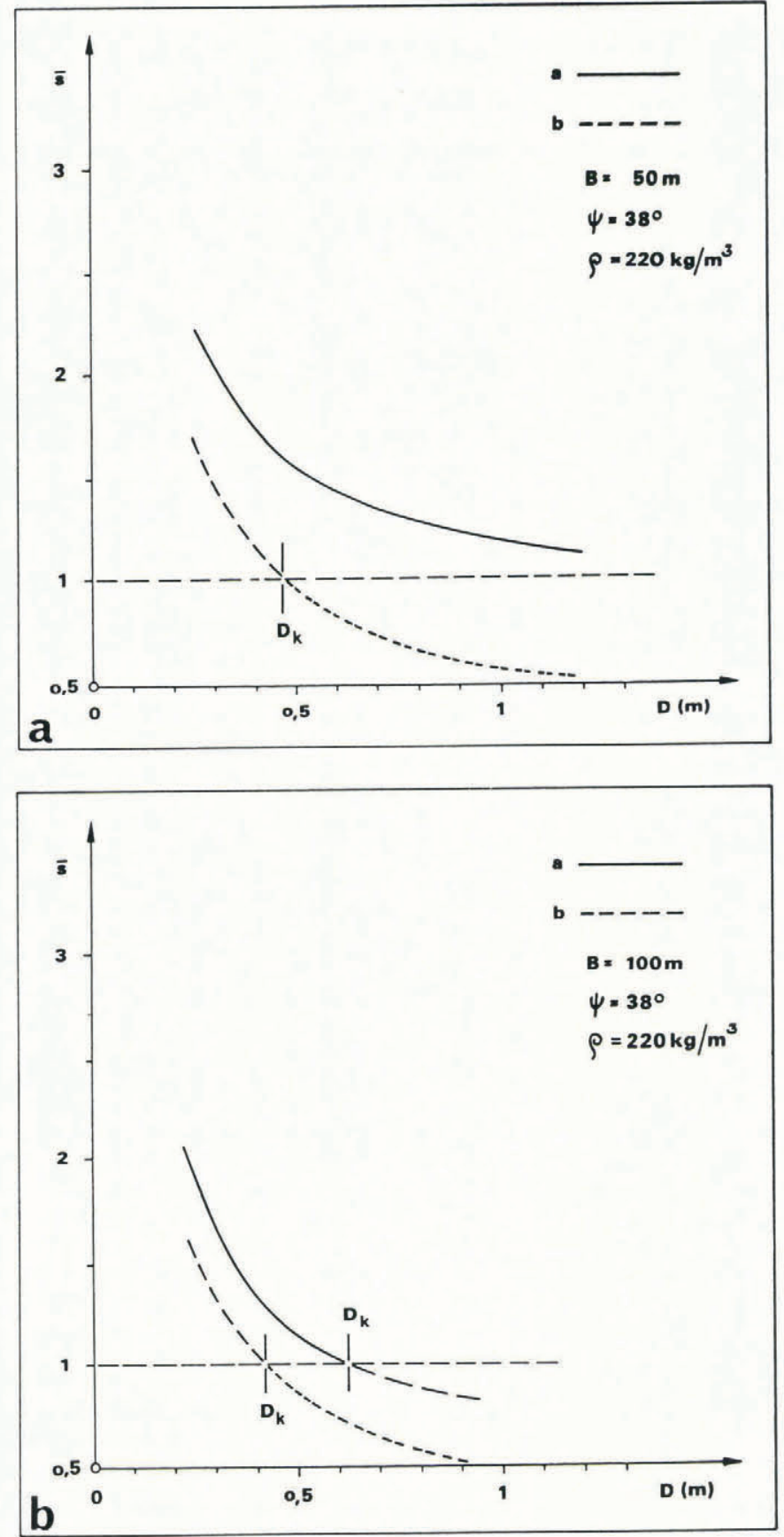

Fig. 5a, b. Integral stability $\bar{s}$ of a snow slab as a function of their thickness $D$. a and b, see Fig. 4. $D_{\mathrm{K}}$, critical thickness $(\bar{s}=1)$.

Setting $\bar{s}=1$, we can compute $D_{\mathrm{K}}$ for constant $B$ and $B_{\mathrm{K}}$ for constant $D$ from Equation (14) as follows:

$$
\begin{aligned}
& D_{\mathrm{K}}=\beta_{\mathrm{S}} B / \rho g \sin \psi\left(B-\beta_{\mathrm{U}} / \rho g \sin \psi\right), \\
& B_{\mathrm{K}}=\beta_{\mathrm{U}} D / \rho g \sin \psi\left(D-\beta_{\mathrm{S}} / \rho g \sin \psi\right) .
\end{aligned}
$$

They are shown in one diagram (Fig. 6).

The hyperbolic shape of the curves means that, with the assumed low shear strength and at small depths, a small increase in depth leads to a very noticeable drop in the maximum possible slab size or, alternatively, in the region with $\bar{s}=1$ in an inclined snow-pack. This region is smaller the lower the circumferential strength (line b, Fig. 6). This favors the spontaneous release of new-snow avalanches. Conversely, hardening of the snow enables larger slabs to remain stable (line a, Fig. 6). When, however, the avalanche is released, e.g. by a skier's forces, it has a larger area.

On the other hand, if a slab avalanche's size is constrained by the topographic relief, a certain depth (the critical depth $D_{\mathrm{K}}$ ) cannot be exceeded. 


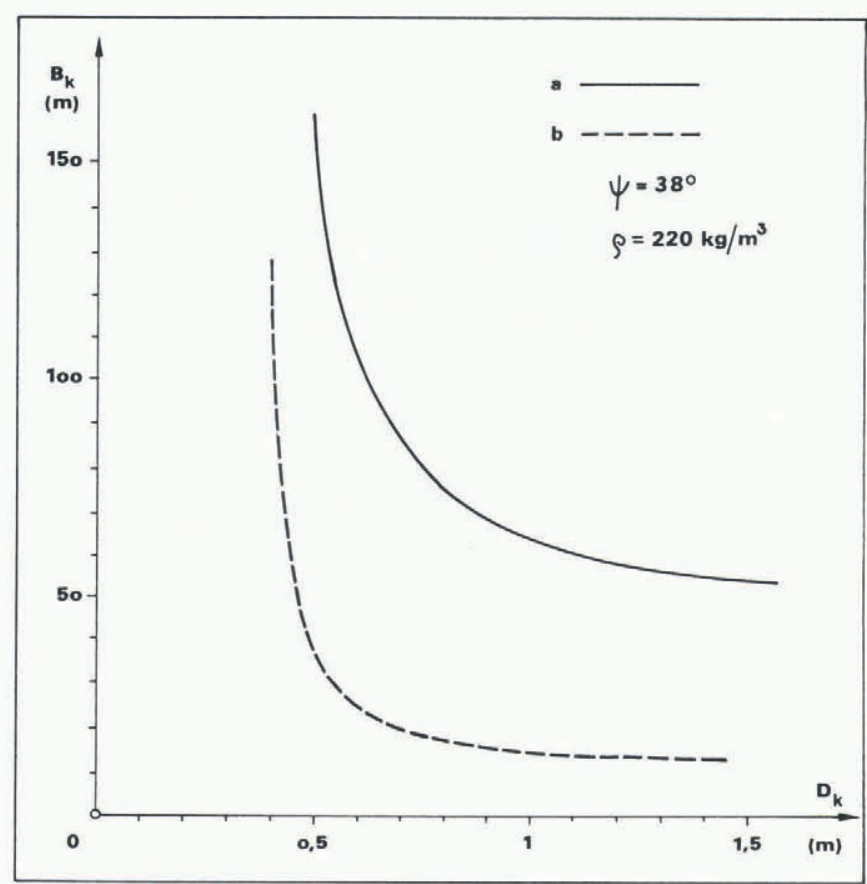

Fig. 6. Critical width $B_{\mathrm{K}}$ in respect of critical thickness $D_{\mathrm{K}}(\bar{s}=1)$ of a snow slab. a and b, see Figure 4 .

\section{CONCLUSIONS}

The first result of the parameter study carried out is confirmation of the overwhelming importance of the shear strength of surfaces parallel to the slope for maintaining the snow-pack's stability. Particularly low strengths should be the preferred objective of intensive future studies, even though they are the most difficult to control in experiments.

The second result, however, is that the boundary conditions play an important role in the process of stress redistribution, particularly when the resisting shear forces are weak. Even with low circumferential strengths, circumferential forces make a considerable contribution to overall stability of a slab; this fraction, however, drops rapidly with increasing avalanche size. Boundary conditions must be increasingly included in theoretical and practical investigations, although, naturally, this will not facilitate the solution of problems connected with avalanche fracture.

Taking note of the great variety of snow types, and of each winter's different time sequence of the weather, both extensive observations and measurements of snow-slab avalanches (geometry, snow data, most of all density, stratification, strengths), as well as further mechanical models of the force interplay, the stresses, deformations, and failure mechanisms will be needed in order to understand better the important and complex problem of snow-slab avalanche release, particularly regarding the processes initiating fracture.

\section{REFERENCES}

Bradley, C.C., R.L. Brown, and T.R. Williams. 1977. Gradient metamorphism, zonal weakening of the snowpack and avalanche initiation. J. Glaciol., 19(81), 335-342.

Bucher, E. 1948. Beitrag zu den theoretischen Grundlagen des Lawinenverbaus. Beitr. Geol. Schweiz, Geotech. Ser., Hydrol. 6.

Conway, H. and J. Abrahamson. 1984. Snow stability index. J. Glaciol., 30(106), 321-327.

Föhn, P. 1981. Schneefeldsprengungen und Stabilität der Schneedecke. In Einfluss von Schneefeldsprengungen auf die Erosion. Kolloquium vom 2. bis 3. Juli 1980. Bayerisches Landesamt für Wasserwirtschaft, 51-70.

Föhn, P.M.B. 1987. The stability index and various triggering mechanisms. International Association of Hydrological Sciences Publication 162 (Symposium at Davos 1986 - Avalanche Formation, Movement and Effects), 195-214.

Gubler, H. 1977. Artificial release of avalanches by explosives. J. Glaciol., 19(81), 419-429.

Gubler, H. 1988. Aspekte der natürlichen Schneebrettauslösung. Eidg. Tech. Hochschule, Zürich. Versuchsanst. Wasserbau, Hydrol. Glaziol. Mitt. 94, 287-305.

Haefeli, R. 1963. Stress transformations, tensile strengths, and rupture processes of the snow cover. In Kingery, W.D., ed. Ice and snow. Cambridge, MA, MIT-Press, 560-575.

Haefeli, R. 1967. Some mechanical aspects on the formation of avalanches. In Ōura, H., ed. Physics of Snow and Ice; International Conference on Low Temperature Science ... 1966 ... Proceedings, Vol. 1, Pt. 2. Sapporo, Hokkaido University. Institute of Low Temperature Science, 1199-1213.

Kupper, W. 1967. Der plastische Grenzzustand in der schiefen ebenen Erd- oder Schneeschicht. Z. Angew. Math. Phys., 18, 705-735.

Mellor, M. 1975. A review of basic snow mechanics. International Association of Hydrological Sciences Publication 114 (Symposium at Grindelwald 1974 - Snow Mechanics), 251-291.

Perla, R.I. 1977. Slab avalanche measurements. Can. Geotech. J., 14(2), 206-213.

Perla, R.I. 1980. Avalanche release, motion, and impact. In Colbeck, S.C., ed. Dynamics of snow and ice masses. New York, Academic Press, 397-462.

Roch, A. 1966a. Les déclenchements d'avalanches. International Association of Scientific Hydrology Publication 69 (Symposium at Davos 1965 - Scientific Aspects of Snow and Ice Avalanches), 182-195.

Roch, A. 1966b. Les variations de la résistance de la neige. International Association of Scientific Hydrology Publication 69 (Symposium at Davos 1965 - Scientific Aspects of Snow and Ice Avalanches), 86-99.

Sommerfeld, R.A. 1969. The role of stress concentration in slab avalanche release. J. Glaciol., 8(54), 451-462.

Ziegler, H. 1963. Methoden der Plastizitätstheorie in der Schneemechanik. Z. Angew. Math. Phys., 14(6), 713-737. 